RESEARCH ARTICLE

\title{
Epidemiological and Genotypical Features of HCV in District Upper Dir, Khyber Pakhtunkhwa, Pakistan
}

\author{
Khaista Munir ${ }^{1}$, Muhammad Ajmal Khan ${ }^{2}$, Aftab Amin ${ }^{3}$, Bakhtawar Khan ${ }^{1}$, Atta Ur Rahman ${ }^{4}$, Amin \\ Ullah $^{5}$, Mukhtar Ullah ${ }^{5}$ \\ ${ }^{7}$ Department of Zoology Hazara university Mansehra KPK, Pakistan \\ ${ }^{2}$ Centre for Biotechnology and Microbiology, University of Peshawar, Peshawar, Khyber Pakhtunkhwa, Pakistan \\ ${ }^{3}$ School of Chinese Medicine and Department of Biology, Hong Kong Baptist University, Hong Kong, China. \\ ${ }^{4}$ Fundação Oswaldo Cruz. Instituto Oswaldo Cruz. Laboratório de Hanseníase. Rio de Janeiro, RJ, Brasil. \\ ${ }^{5}$ Molecular Virology Laboratory, Department of Microbiology and Biotechnology, Abasyn University, Peshawar, \\ Pakistan \\ ${ }^{6}$ Centre of Applied Molecular Biology, University of Punjab, Lahore, Pakistan
}

\begin{abstract}
Objectives: Objective: The incidence of Hepatitis C Virus (HCV) infection is high in Pakistan. The current study evaluates HCV risk factors, epidemiology, and genotype distribution in the lessdeveloped Upper Dir Region, Khyber Pakhtunkhwa Province (KPK), Pakistan.

Methods: Blood samples from 500 outpatients from the Upper Dir Region were collected for initial screening using a strip-based immunochromatography test (ICT). In this study, ICT analysis followed Polymerase chain reaction (PCR) analysis for HCV-RNA confirmation. In addition, PCR positive samples were subject to genotypic description using genotype-specific primers.
\end{abstract}

Results: ICT analysis revealed that out of 500 patients, 13 (2.6\%) were HCV positive. PCR analysis identified that $10(2.0 \%)$ of the $13 \mathrm{HCV}$-positive patients were HCV-RNA positive. The overall incidence of HCV in the study group was $2.6 \%$. The rate of HCV incidence was found to be higher in males (10/339 participants, 3.0\%), while a lower incidence was found in females (3 of 161 participants, 1.9\%). The patients between 45 and 60 years had the highest incidence rate ( 6 of 53 participants, $11.3 \%$, $\mathrm{P}<0.05$ ); while the patients between 25 and 44 years had an incidence rate of $4.2 \%$ (7 of 166 participants). Different HCV subtypes were also detected; $1 \mathrm{a}$ (two participants), $2 \mathrm{~b}$ (one participant), $3 \mathrm{a}$ (two participants) and 3b (two participants). Three of the patients had untypable (UT) HCV genotype variants.

Conclusion: The study results suggest that; most of the cases were males and between 25 and 60 year-old. At the same time, several HCV subtypes are present in the inhabitants of the study area. Therefore, the presence of untypable genotypes may lead to diagnostic and therapeutic difficulties or failures. J Microbiol Infect Dis 2021; 11(4):218-224.

Keywords: Genotypes, Hepatitis C Virus, incidence, Untypable

\section{INTRODUCTION}

Hepatitis $C$ is an infectious disease that causes liver inflammation. The Hepatitis C Virus (HCV) belongs to the Flaviviridae family of RNA viruses discovered in 1989 by Choo and his coworkers as the major cause of non-
$A$ and non-B hepatitis (NANB) [1]. It is an enveloped virus that has a genome size of $9.6 \mathrm{~kb}$ flanked by an untranslated region (UTR) at both 5' and 3' ends. The HCV genome encodes 3008-3037 amino acids that are posttranslationally processed to produce three

Correspondence: Muhammad Ajmal Khan, Centre for Biotechnology and Microbiology, University of Peshawar, Peshawar, 
structural proteins (SP) and six non-structural (NS) proteins [2].

The Prevalence of HCV varies from country to country [3]. The World Health Organization (WHO) estimates that global prevalence is approximately $3 \% \quad(200$ million people worldwide), with 3-4 million new infections annually [3,4]. Developing nations in Africa and Asia have the highest prevalence rates [5]. The pattern of HCV distribution is uneven in the Asia (4\%) and Pacific regions (12\%) [6]. Prevalence rates are highest in China (3.2\%), Indonesia (2.1\%), Saudi Arabia (1.8\%) and India $(1 \%)[7,8]$. HCV infection rates in Europe are approximately $1 \%$ [9]. HCV infections spread rapidly in Pakistan, with approximately 10 million people (5\% of the entire population) being infected [10]. In Pakistan, the distribution pattern of $\mathrm{HCV}$ is different in different geographical regions and even communities within a given area [11]. Many factors such as improper use of medical equipment by healthcare practitioners, needle sharing amongst drug abusers, non-hygienic practices in the service sectors (salons, barbershops, etc.), lack of public awareness, and unscreened blood transfusions contribute to the high prevalence rate of the infection in Pakistan [12].

Phylogenetically, six major genotypes of HCV have been reported based on nucleotide heterogeneity (35\%). Each genotype is further divided into sub-genotypes, giving more than 100 sub-genotypes [13]. The dominant genotypes circulating across the globe are type 1 and 3. The most prevalent genotype in Pakistan is 3 , with sub-genotype $3 a$ being dominant [14]. Many studies have reported on the Prevalence of $\mathrm{HCV}$ in major Pakistani cities. However, none of these studies have reported HCV epidemiology, genotype distribution, and other covariates, such as age and gender in underdeveloped country areas. The current study aims to determine HCV incidence and genotype distribution in areas of Upper Dir. In addition, there is a general lack of HCV awareness due to poor education, lowsocioeconomic conditions, and a lack of medical facilities.

\section{METHODS}

\section{Ethical Consideration}

All the experiments and procedures performed in this study were approved by the Ethics
Committee of the Department of Zoology, Hazara University, Mansehra, Pakistan (Permit number: HU/2015/03/20/100A).

\section{Study Area}

This study was conducted in Upper Dir, Khyber Pakhtunkhwa, Pakistan $\left(35^{\circ} \mathrm{N}\right.$ latitude, $72^{\circ} \mathrm{E}$ longitude). Upper Dir spans an area of $3,699 \mathrm{~km} 2$ and has a population of approximately 0.946 million people, according to the 2017 census. This region was selected for the study owing to its unique socioeconomic environment. However, the majority of the inhabitants have a lack education and awareness.

\section{Blood Sampling}

Blood samples from 500 patients who inhabitants of the Upper Dir Region were collected when they applied to the different local hospitals (Category D Hospital Wari, Rural Health Centre, Dislawar, Category D Hospital Chapar, DHQ Hospital, Upper Dir). Patients attending these hospitals with HCVrelated symptoms, such as fatigue, poor appetite, itchy skin, bruising, yellow discoloration of the skin and eyes, etc., were included in this study. There were no age and gender restrictions in participation in the study.

Individuals who failed to provide the necessary details, such as information regarding their symptoms, associated risk factors, and contact information, were excluded from the current study.

Patients' personal data such as their name, age, gender, address, and contact information were recorded. The written consent was obtained from participants and/or the parents or guardians of participants. Blood samples were collected in proper tubes and labeled. Samples were spun down at $4000 \times \mathrm{g}$ for 10 minutes to obtain sera. The sera were appropriately stored under refrigeration at $20^{\circ} \mathrm{C}$ for further use.

\section{Immunochromatographic Test (ICT)}

For initial screening, a one-step Anti-HCV strip-based immunochromatographic test (ICT) (ACON® Lab. Inc., San Diego, CA 92121, USA) was used following the manufacturer's protocols to detect Anti-HCV antibodies [15]. In addition, ICT positive samples were subject to further molecular detection and genotype analysis. 


\section{HCV confirmation by PCR}

Nested reverse transcription PCR (RT-PCR) was carried out using ICT positive samples for HCV-RNA detection as previously described [16]. Briefly, RNA was isolated from $250 \mu \mathrm{L}$ of serum using Trizol reagent (15596018, Life Technologies) according to the manufacturer's instructions. The extracted RNA was stored at $-80^{\circ} \mathrm{C}$ for RT-PCR. Moloney murine leukemia virus (MMLV) reverse transcriptase enzyme (Invitrogen, Corp., California USA) was used for cDNA synthesis. A reverse primer (5'GTG CAC GGT CTA CGA GAC CT3') specific to the HCV genome was used for cDNA synthesis. The reaction mixture for cDNA synthesis containing nuclease-free water $(3 \mu \mathrm{L}), 5 X$ reaction buffer $(4 \mu \mathrm{L})$, dNTPs $(1 \mu \mathrm{L})$, Moloney-Murine Leukemia Virus Reverse transcriptase $(1 \mu \mathrm{L})$, RNA template $(10 \mu \mathrm{L})$, reverse primer $(1 \mu \mathrm{L})$. The reaction mixture was kept in a thermal cycler for 1 hour at $42^{\circ} \mathrm{C}$ followed by $90^{\circ} \mathrm{C}$ for 2 minutes.

A $20 \mu \mathrm{l}$ reaction mixture containing Taq DNA Polymerase (Fermentas Technologies USA) was prepared for Nested PCR for PCR confirmation of ICT positive samples. The amplified PCR product was run on $2 \%$ agarose gel for the detection of a specific HCV band. The positive samples were further subjected to qualitative PCR using an RNA quantification kit (Sacace, Biotechnologies, Italy) and Smart Cycler-II Real-time PCR machine (Cepheid, Calif, and Sunnyvale, USA).

\section{HCV genotyping}

HCV genotyping was carried out as described previously [17] using type-specific HCV primers to genotype all HCV-positive samples. Briefly, cDNA was synthesized using $100 \mathrm{U} / \mu \mathrm{L}$ of $\mathrm{M}-\mathrm{MLV}\left(42^{\circ} \mathrm{C}, 60 \mathrm{~min}\right)$. Two microliters of cDNA were used in the first round of PCR to amplify a 470 bp HCV region (5'NCR along with core region). Two primers (SC2 and AC2) were used in this process. The reaction was carried out in $20 \mu \mathrm{l}$ volume containing nuclease-free water $(9.3 \mu \mathrm{l}), 10 \mathrm{x}$ buffer $(2 \mu \mathrm{l})$, $\mathrm{MgCl} 2(1.5 \mu \mathrm{l}, 25 \mathrm{Mm})$, dNTPs $(1 \mu \mathrm{l}, 2.5 \mathrm{Mm})$, Primer AS2 $(1 \mu \mathrm{l})$, Primer AC2 $(1 \mu \mathrm{l})$, DNA template $(4 \mu \mathrm{l})$ and Taq polymerase $(0.2 \mu \mathrm{l}, 5$ $\mathrm{U} / \mu \mathrm{L})$. The first-round PCR profile was; $94^{\circ} \mathrm{C}$ for 2 min (Pre-denaturation), followed by 30 cycles at $94^{\circ} \mathrm{C}$ for $30 \mathrm{sec}$ (denaturation), $45^{\circ} \mathrm{C}$ for $1 \mathrm{~min}$ (annealing), and $72^{\circ} \mathrm{C}$ for $1 \mathrm{~min}$ (extension). The final extension was $72^{\circ} \mathrm{C}$ for $10 \mathrm{~min}$. The samples were stored at $4^{\circ} \mathrm{C}$ until further use. The reaction was carried out using an automatic thermal cycler (ABIPCR system $2700)$. In the second round of PCR, two primers were used to identify the HCV genotypes. Two nested PCR reaction mixtures were prepared, each having two sets of primers (Table 1). Genotypes 1b, 2a, 2b, and $3 b$ were identified using reaction mixture one, while genotypes $1 \mathrm{a}, 3 \mathrm{a}, 4,5 \mathrm{a}$, and $6 \mathrm{a}$ were identified using reaction mixture two. The second-round PCR profile was the same as the first. The amplified PCR product from the second round of PCR was run on a $2 \%$ agarose gel to identify a genotype-specific fragment.

\section{Statistical analysis}

SPSS statistical software version 16.0 was used for data analysis and tabulation. Statistical significance of the data was evaluated by Chi-square test, and the data were shown as mean values or number of patients. A $p$-value $>0.05$ was considered to be statistically significant.

\section{RESULTS}

\section{Patient Demography}

In total, 500 individuals were screened from the Upper Dir area. Of the 500 patients, 339 $(67.2 \%)$ were male, and $161(32.2 \%)$ were female. The participants were divided into different age groups; age group I (10-24 years) consisting of $267(53.4 \%)$ individuals, age group II (25-44 years) consisting of 166 (33.2\%) individuals, age group III (45-60 years) consisting of $53(10.6 \%)$ individuals and age group IV (61-75 years) consisting of 14 $(2.8 \%)$ individuals. Data analysis showed that the overall incidence of HCV recorded in Upper Dir during the current study was $2.6 \%$ (13 of 500 participants).

\section{ICT and PCR Confirmation for HCV}

All the blood samples were initially screened for anti-HCV antibodies by ICT. The results showed that out of 500 individuals, 13 (2.6\%) tested positive. Although the antibody-based ICT is a good indicator of HCV, the $13 \mathrm{HCV}$ positive samples were further examined by PCR to detect HCV-RNA. Out of 13 samples, ten were found to be HCV RNA reactive, while three samples were found to be non-reactive. The viral load detected in the positive samples was in the range of $1.5 \times 103$ to $2.8 \times 106$ $\mathrm{IU} / \mathrm{ml}$. 


\section{Incidence of HCV by Gender}

The incidence of $\mathrm{HCV}$ was found more prevalent among males (ICT, 3.0\%) compared to females (ICT, 1.9\%) (Table 2). PCR confirmation showed that $2.4 \%$ of males were infected, while only $1.2 \%$ of females were HCV positive. However, these differences were not statistically significant $(P>0.05)$.

\section{Incidence of $\mathrm{HCV}$ by Age}

The next covariate that we analyzed was age (Table 3). Our analysis showed that age group III had the highest Prevalence (ICT, 11.3\%; $7.5 \%, \mathrm{PCR}$ ), followed by age group II (ICT, $4.2 \%$; PCR, $3.6 \%$ ). HCV-positive individuals were not detected in the remaining two age groups (I\&IV). Individuals in age group IV were asymptomatic. Statistical analysis revealed that the differences between the four age groups were statistically significant $(P<0.05)$.

\section{HCV genotypes circulating in the Upper Dir Region}

PCR positive samples were genotyped to determine which were the most prevalent genotype circulating in Upper Dir (Figure 1). Out of samples, seven samples had typespecific bands, while three samples had UT genotypes. The incidence of the genotypes was as follows: 1a (two patients), $2 \mathrm{~b}$ (one patient), 3a (two patients), 3b (two patients). Gender-wise genotypic distribution showed that out of 2 ICT positive females, 1 was UT, while the other had genotype 3a. In eight infected male subjects, $25 \%$ were UT, while the remaining had genotype 1a (25\%), $2 b$ $(15.5 \%), 3 \mathrm{a}(12.5 \%)$ and $3 \mathrm{~b}(25 \%)$.

\section{DISCUSSION}

Upper Dir is a relatively new district of KPK Province in Pakistan. This district is predominately mountainous and surrounded by forests. Poor infrastructure has left this area severely underdeveloped. In this study, we have determined the incidence and genotypic distribution of HCV among the natives of Upper Dir. This district was selected because of its prime geographical locations and lessening education resources to spread awareness among its inhabitants regarding HCV. Random sampling was carried out in a mixed population of individuals. Age restrictions were not applied to encourage participation.
The molecular epidemiology of $\mathrm{HCV}$ is different across different regions and groups [18]. In the general population of Pakistan, the seroprevalence of HCV is very high, approximately $6 \%$ [11]. The epidemiology of HCV recorded in the present study $(2.6 \%)$ was comparatively less than that recorded in previous studies that focused on major cities, such as Islamabad (5.31\%) [18], Faisalabad (20.89\%) [19], Multan (4.06\%) [18], Karachi (4$6 \%$ [20], Mardan (9\%) [21] and Bunir (5\%) [22].

A significant difference was observed in $\mathrm{HCV}$ incidence among different age groups. Age groups II \& III were found to have a higher HCV prevalence compared to age groups I \& IV. Interestingly, HCV-positive individuals in these groups went through dental surgery, identifying it as a potential risk factor. Unsterilized instruments for dental procedures in these poor areas is a likely source of infection. The high infection rates in adults can also be attributed to their frequent exposure to potential risk factors in their daily lives; for example, many patients regularly visited salons and barbershops where new blades were seldom used. The results of this study are consistent with previous reports, which suggest that HCV is highly prevalent among middle-aged individuals [23].

The HCV genome has high genetic variability, with a nucleotide substitution rate of $1.44 \times 10^{-3}$ - $1.92 \times 10^{-3}$ per site/year [24]. The high substitution rate in HCV results in different genotypes. Currently, six major genotypes and more than 100 subtypes have been identified. These diverse genotypes affect drug response in HCV-infected individuals [25]. Genotypes 2a and $3 \mathrm{a}$ are prevalent in the major cosmopolitan cities of various countries around the world [19]. Studies have shown that genotype $3 a$ is the most predominant genotype in Pakistan (approximately 70\%) [26]. Our genotypic analysis indicates that genotypes 1a (20\%), 3a (20\%), and $3 b(20 \%)$ are equally prevalent among the people of Upper Dir. These results substantiate the findings of a previous study which shows that genotype $3 a$ is the predominant genotype in Pakistan, followed by $1 \mathrm{a}$ and $3 \mathrm{~b}$ [23, 27, 28]. In our study genotype, $2 \mathrm{~b}$ was also detected in 1 infected person. This genotype is very rare in Pakistan, and its occurrence in the local population has been linked to the movement of people to North America, Europe, and Japan, 
where it is frequently observed [29]. Interesting several UT genotypes were present in our study. UT genotypes have been previously reported in earlier studies carried out in Pakistan $[30,23]$, indicating that it may be a growing healthcare issue in Pakistan. The higher occurrence of UT genotypes indicates that patients may have undergone interferon therapy or that the current genotype detection method failed to identify the genotype [25]. Conceivably, some novel genotypes may exist in Pakistan [23]. Novel, sensitive and reliable methods must be developed to detect untypable HCV genotypes.

Table 1. Oligonucleotide used for the $1^{\text {st }}$ and $2^{\text {nd }}$ round of PCR for HCV genotyping.

\begin{tabular}{|c|c|c|}
\hline Primers & Sequence & Nucleotide Position \\
\hline $\mathrm{SC2}$ & $\begin{array}{l}\text { 5-GGG AGG TCT CGT AGA CCG TGC ACC ATG- } \\
3 \text {, }\end{array}$ & $24-3$ \\
\hline AC2 & $\begin{array}{c}- \text { GAG(AC)GG } \\
\text { (GT)AT(AG)TACCCCATGAG(AG)TCGGC-3 }\end{array}$ & $417-391$ \\
\hline \multicolumn{3}{|c|}{ (2) } \\
\hline S7 & 5-AGACCGTGCACCATGAGCAC-3' & $12--18$ \\
\hline S2a & 5'-AACACTAACCGTCGCCCACAA-3' & $40-60$ \\
\hline G1b & 5'-CCTGCCCTCGGGTTGGCTA (AG)-3' & $222-203$ \\
\hline G2a & 5-CACGTGGCTGGGATCGCTCC-3' & $178-159$ \\
\hline G2b & 5'-GCCCCAATTAGGACGAGAC-3' & $325-306$ \\
\hline \multicolumn{3}{|l|}{ Mix 2} \\
\hline S7 & 5'-AGACCGTGCACCATGAGCAC-3' & $12--18$ \\
\hline G1a & 5'-GGATAGGCTGACGTCTACCT-3' & 196-177 \\
\hline G3a & 5'-GCCCAAGGACCGGCCTTCGCT-3' & $220-211$ \\
\hline G4 & 5'-CCCGGGAACTTAACGTCCAT-3' & $87-58$ \\
\hline G5a & 5'-GAACCTCGGGGGGAGAGCAA-3' & $308-289$ \\
\hline G6a & 5'-GGTCATTGGGGCCCCAATGT-3' & $334-315$ \\
\hline
\end{tabular}

Table 2. Prevalence of HCV by gender.

\begin{tabular}{lccc}
\hline Gender & No. of Samples & Anti-HCV Antibody Positive Cases, $\mathrm{n}(\%)$ & HCV-PCR Positive Cases, $\mathrm{n}(\%)$ \\
\hline Male & 339 & $10(3.0)$ & $8(2.4)$ \\
Female & 161 & $3(1.9)$ & $2(1.2)$ \\
Total & 500 & $13(2.6)$ & $10(2.0)$ \\
\hline
\end{tabular}

Table 3. Prevalence of HCV by age groups.

\begin{tabular}{cccc}
\hline Age groups & Samples & Anti HCV Antibody Positive cases (\%) & HCV PCR Positive cases (\%) \\
\hline $10-24$ years & 267 & $0(0.0)$ & $0(0.0)$ \\
$25-44$ years & 166 & $7(4.2)$ & $6(3.6)$ \\
$45-60$ years & 53 & $6(11.3)$ & $4(7.5)$ \\
$61-75$ years & 14 & $0(0.0)$ & $0(0.0)$ \\
\hline
\end{tabular}

This study has some limitations also. As many chronic HCV patients do not have specific symptoms until the disease has significantly progressed, this study cannot screen for such 
individuals. Therefore, individuals suspected to be HCV positive were included in the study. Furthermore, HCV prevalence could only be examined in 500 participants due to a lack of funding. This also limited the number of variables that could be examined. These issues must be addressed better to understand HCV spread and infection in Upper Dir.

\section{Conclusion}

Hepatitis C infection is highly prevalent in Upper Dir. Residents of the area are unaware of the causes, symptoms, and preventive methods. The lack of education and knowledge contributes to the spread of the virus and may lead to higher mortality and morbidity rates in the future. Therefore, local authorities must take appropriate action to spread HCV awareness among the inhabitants in the district. This study has laid the foundation for future studies that must include more areas, participants, and molecular approaches to address the issue broadly.

\section{ACKNOWLEDGMENTS}

The authors are indebted to Hazara University, Mansehra, and Peshawar for assigning us space to carry out our experiments.

Declaration of conflicting interest: The author(s) declare no potential conflicts of interest concerning this article's research, authorship, and/or publication.

Financial disclosure: No financial support was received for this study. However, the authors would like to thank faculty members of Hazara University (Department of Zoology) and the University of Peshawar (Centre of Biotechnology and Microbiology) for providing reagent support and access to scientific equipment.

\section{REFERENCES}

1. Choo QL, Kuo G, Weiner AJ, et al. Isolation of a cDNA clone derived from a blood-borne non-A, non-B viral hepatitis genome. Science 1989; 244 (4902):359-362.

2. Argentini C, Genovese D, Dettori S, Rapicetta M. HCV genetic variability

from quasispecies evolution to genotype classification. Future Microbiol 2009; 4(3):359373.

3. WHO. Diseases; Hepatitis C. http://www.who.int/csr/disease/hepatitis/wh ocdscsrlyo2003/en/index3.html. Accessed in 2017.

4. Wild CP, Hall AJ. Primary prevention of hepatocellular carcinoma in developing countries. Mutat Res 2000; 46(2-3):381-393.

5. Hanafiah K, Groeger J, Flaxman A, Wiersma S. Global epidemiology of hepatitis $C$ virus infection: new estimates of age-specific antibody to HCV seroprevalence. Hepatology 2013; 57(4):1333-1342.

6. Raza S, Mubeen H, Farooqi S. Review: epidemic status of HCV in Pakistan. Glob $\mathrm{J}$ Engin Sci Res Man 2015; 12(2):

7. Ruan Y, Qin G, Yin L, Chen K, Qian H, Hao C. Incidence of HIV, hepatitis $\mathrm{C}$ and hepatitis $\mathrm{B}$ viruses among injection drug users in southwestern China: a 3-year follow-up study. AIDS 2007; 21(8): S39-46

8. Al-Tawfiq J, Anani A. Profile of viral hepatitis a, $B$, and $C$ in a Saudi Arabian hospital. Med Sci Monit 2008; 14(1):56-52

9. Touzet S, Kraemer L, Colin C et al. Epidemiology of hepatitis $C$ virus infection in seven European Union countries a critical analysis of the literature. HENCORE Group. (Hepatitis C European Network for Cooperative Research). EUR J Gasterno Hepat 2000; 12(6):667-678

10. Waheed Y, Saeed U, Safi SZ, Chaudhry WN, Qadri I. Awareness and risk factors associated with barbers in transmission of hepatitis $B$ and $C$ from Pakistani population barber's role in viral transmission. Asian Biomed 2010; 4(3):435-442.

11. Muzaffar F, Hussain I, Haroon TS. "Hepatitis C: the dermatologic profile." J. Pak Assoc 2008; 18(3):171-181.

12. Ashraf S, Ahmad A. Viral hepatitis in Pakistan: challenges and priorities. Asian Pac J Trop Biomed 2015; 5(3):190-191.

13. Hnatyszyn HJ. Chronic hepatitis C and genotyping: the clinical significance of determining HCV genotypes. Antivir Ther 2005; 10(1):1-11.

14. Khan $T$, Mehr $M$, Ullah $H$, Khan $H$, Iman $N$. Frequency of hepatitis $\mathrm{C}$ genotypes in the north of Pakistan. Gomal J Med Sci 2014; 12(2):9106.

15. Abou, MAA, Eltahir YM, Ali, AS. Seroprevalence of hepatitis $B$ virus and hepatitis $C$ virus among blood donors in Nyala, South Dar Fur, Sudan. Virology 2009; 6(1):146-156.

16. Idrees M. Common genotypes of hepatitis C virus present in Pakistan. Pak J Med Res 2001; 40 (2): 46-49 
17. Idrees M. Development of an improved HCV Genotyping Assay for the Detection of Common Genotypes and subtypes in Pakistan. J Virol Meth 2008; 150(1-2);50-56.

18. Idrees M, Lal A, Naseem M, Khalid M. High prevalence of hepatitis $C$ virus infection in the largest province of Pakistan. J Dig Dis 2008; 9(2):95-103.

19. Ahmad N, Asgher M, Shafique M, Qureshi JA. "An Evidence of high prevalence of Hepatitis C virus in Faisalabad, Pakistan. Saudi Med J 2007; 28(3):390.

20. Khan NU, ljaz A, Naeem U, et al. prevalence of active HCV infection among the blood donors of Khyber Pakhtunkwa and FATA region of Pakistan and evaluation of the screening tests for anti-HCV. Virol J 2011; 8(1):1-3.

21. Ali A, Ahmed $H$, Idrees M. Molecular epidemiology of Hepatitis $C$ virus genotypes in Khyber Pakhtunkhwa of Pakistan. Virol J 2010; $7(1): 1-7$

22. Muhammad N, Jan MA. 2005. Frequency of hepatitis" C" in Buner, NWFP. J Coll Physicians Surg Pak 2005; 15(1):11-14.

23. Inamullah I, Idrees $M$, Ahmed $H$, Ali M, Ali L, Ahmed A. Hepatitis $C$ virus genotypes circulating in district Swat of Khyber Pakhtoonkhaw, Pakistan. Virol J 2011; 8(1): 1-5.

24. Ogata N, Alter $\mathrm{HJ}$, Miller $\mathrm{RH}$, Purcel $\mathrm{RH}$. Nucleotide sequence and mutation rate of the $\mathrm{H}$ strain of hepatitis $C$ virus. Proc Natl Acad Sci USA 1991; 88(8): 3391-3396.

25. Ohno O, Mizokami M, Wu RR, et al. New hepatitis $\mathrm{C}$ virus ( $\mathrm{HCV}$ ) genotyping system that allows for identification of HCV genotypes $1 \mathrm{a}$, 1b, 2a, 2b, 3a, 3b, 4, 5a, and 6a. J clin Microbiol 1997; 35(1):201-207.

26. Rehman I, Idrees M, Ali M, et al. Hepatitis C Virus genotype $3 a$ with phylogenetically distinct origin is circulating in Pakistan. Genet Vaccine Ther 2011; 9(1):212-215.

27. Khan MA, Khan SA, Hamayun M, Ali M, Idrees $M$. Sequence variability of $\mathrm{HCV} 3 \mathrm{a}$ isolates based on core gene in patients from Lahore, Pakistan. Future Virol 2019; 14(10):641-653.

28. Ahmad W, ljaz B, Javid TF, et al. HCV genotype distribution and possible transmission risks in Lahore, Pakistan. Gastroenterol 2010; 16(36): 4321-4328.

29. Idrees M, Ur Rehman I, Manzoor $S$ et al. Evaluation of three different hepatitis $C$ virus typing methods for detection of mixed-genotype infections. J dig dis 2011; 12(3):199-203.

30. Saleha S, Kamal A, Ullah F, Khan N, Mahmood A, Khan S. Prevalence of hepatitis $C$ virus genotypes in district Banu, Khyber Pakhtunkhwa, Pakistan. Hepat Res Treat 2014; 2014:1-5. 